\title{
Diagnostic yield of ultrasound-guided transthoracic biopsy in peripheral lung lesions
} Fayed H. Kawshty ${ }^{\mathrm{a}}$, Ahmed A. Abd Elradi ${ }^{\mathrm{b}}$, Ahmed M. Ahmed

\begin{abstract}
Background Ultrasonography (US) guidance of transthoracic needle biopsy of peripheral lung lesions is a useful diagnostic technique. It is a relatively easy and safe procedure under real-time US guidance and may give enough tissue sampling of lesions for histopathological examination. The aim of this study was to determine the diagnostic accuracy and safety of this technique in the diagnosis of peripheral lung lesions.
\end{abstract}

Patients and methods A total of 60 patients underwent USguided percutaneous needle biopsy of peripheral lung lesions from November 2017 to October 2018 in the Chest Department. The age of patients ranged from 27 to 79 years, with mean age of 58.4 years. Overall, $48(80 \%)$ patients of the studied group were males, whereas $12(20 \%)$ patients were females.

Results According to the final diagnoses, 48 (80\%) cases were malignant and $12(20 \%)$ cases were benign. Diagnostic accuracy was $90 \%$, sensitivity was $96 \%$, both specificity and positive predictive value were $100 \%$, and the negative

\section{Introduction}

Peripheral pulmonary lesions (PPLs) are very common, with an increase in frequency of its identification in recent years. PPLs are outlined as lesions adjacent to the pleura and having an accessible window for the ultrasound (US). PPLs are solid or fatty solid nodule present beyond the visible range of flexible bronchoscopy, detected by chest radiography and computed tomography (CT), which may be arising from lung, pleura, chest wall, or mediastinum $[1,2]$.

Chest US is an effective and safe method for evaluation of lesions in the lung periphery, the chest wall, pleural cavity, and mediastinum. US guidance of needle biopsy to obtain specimens for histopathological examination provides real-time imaging of the procedure. USguided percutaneous transthoracic needle biopsy has many advantages over other imaging techniques such as less exposure of the patient to radiation, acceptability, rapid, inexpensive, and bedside procedure. US-guided techniques are especially suitable for individuals who are more susceptible to injury from radiation, such as infants and pregnant women, and for patients who are difficult to move [3].

Percutaneous transthoracic needle biopsy is a wellestablished diagnostic procedure. It has been identified as playing a crucial role in diagnosing many pulmonary lesions [4]. predictive value was $60 \%$. Pneumothorax and hemoptysis occurred in two (3.33\%) patients each.

Conclusion Chest US-guided biopsy in the diagnosis of peripheral lung lesions is a safe and fast procedure with high diagnostic yield and fewer complications.

Egypt J Bronchol 2019 13:469-476

(C) 2019 Egyptian Journal of Bronchology

Egyptian Journal of Bronchology 2019 13:469-476

Keywords: diagnostic accuracy, lung biopsy, lung, transthoracic biopsy, ultrasound

Departments of, ${ }^{\mathrm{a}}$ Chest Diseases, ${ }^{\mathrm{b}}$ Radiological, ${ }^{\mathrm{C}}$ Pathology, Al-Azhar University, Assiut, Egypt

Correspondence to Fayed H. Kawshty, MD, Al Forsan Building, Al-Azhar Street, Assiut City, Assiut, Egypt. Tel: +20 109332 6825; fax: 02882149358;

e-mail: kawshtey1978@yahoo.com

Received: 15 March 2019 Revised: 5 April 2019

Accepted: 8 April 2019 Published: 25 October 2019

The purpose of our study was to evaluate the safety and diagnostic accuracy of transthoracic US-guided needle biopsy in the diagnosis of PPLs.

\section{Patients and methods}

The study was carried out at Chest Department during the period from November 2017 to October 2018. It included 60 patients with undiagnosed PPLs as evidenced by chest radiography (posteroanterior and lateral views) and recent contrast-enhanced chest $\mathrm{CT}$. All patients underwent real-time US before biopsy to detect its diagnostic outcome. The study was approved by the local ethical committee of our university to evaluate and publish information. After explaining the study details to the patients, written or verbal consent was taken from all patients.

\section{Inclusion criteria}

Patients were selected upon the presence of a mass on the chest radiograph with accessible US window (not under rib or retrosternal) and no intervening normal parenchymal tissue between pleural surface and lesion. All patients would have to be fully conscious and fit for the procedure.

This is an open access journal, and articles are distributed under the terms of the Creative Commons Attribution-NonCommercial-ShareAlike 4.0 License, which allows others to remix, tweak, and build upon the work non-commercially, as long as appropriate credit is given and the new creations are licensed under the identical terms. 


\section{Exclusion criteria}

The following were the exclusion criteria: (a) Bleeding diseases (activated partial thromboplastin time ratio or international normalized ratio more than 1.3 or platelet count less than $50000 / \mathrm{mm}^{3}$ ); (b) cardiovascular instability, such as uncontrolled severe hypertension; (c) lack of patient cooperation, for example, altered consciousness; (d) contralateral pneumonectomy; (e) borderline respiratory failure $\left(\mathrm{SaO}_{2}, 85-90 \%\right)$ and patient on mechanical ventilation; ( $\mathrm{f}$ ) hypervascular lesion or aneurysm; (g) severe chronic obstructive pulmonary disease (forced expiratory volume in $1 \mathrm{~s}<11$ or $<35 \%$ predicted); (h) pyogenic cutaneous lesion (pyoderma); and (i) patient refusal.

\section{Methods}

All patients underwent the following: (a) history taking and clinical examination; (b) chest radiograph (posteroanterior and lateral views) before and after the maneuver; (c) recent $\mathrm{CT}$ chest with nonionic contrast media before the biopsy; (d) laboratory studies, such as complete liver functions, kidney functions, complete blood count, erythrocyte sedimentation rate, and blood sugar; (e) preprocedural evaluation, such as pulmonary function tests, arterial blood gases, ECG, and coagulation profile (including bleeding and clotting times, prothrombin time and activity, and activated partial thromboplastin time) with the consideration that oral anticoagulants were stopped before the procedure for at least $48 \mathrm{~h}$; (f) chest US for all patients using highresolution real-time US; (g) color Doppler US by the same device in suspected vascular lesions; (h) clinical and radiological follow-up of patients over 1 week after the procedure to detect the occurrence of any complications; and (i) histopathological examination of biopsy samples.

\section{Results}

This study included 60 patients with peripheral lung lesions; of them, 48 (80\%) patients were males, whereas $12(20 \%)$ patients were female. Their age ranged from 27 to 79 years, with a mean age of 57.7 years. The smoking status among patients was $73.3 \%$ smokers and $26.7 \%$ nonsmokers (Table 1). The maximum number of patients were with a lesion on right upper zone, and next came left upper zone. The mean size of the lesions was $5.90 \pm 1.4 \mathrm{~cm}(3-8 \mathrm{~cm})($ Table 1$)$.

Most of the patients presented with chest pain (80\%) and hemoptysis (73.3\%), which is indicative of the lesion to be peripheral, close to the chest wall (Table 2).

Conclusive diagnosis with an initial biopsy was obtained in 54 (90\%) of 60 procedures. Biopsies
Table 1 Sociodemographic characteristics among patients, size, and location of the lesion and complication $(N=60)$

\begin{tabular}{lc}
\hline Age (years) & \\
Mean \pm SD & $58.4 \pm 13.4$ \\
Range & $68.2(27-79)$ \\
Age groups (years) $[n(\%)]$ & \\
20-30 & $4(6.7)$ \\
$31-40$ & $4(6.7)$ \\
$41-50$ & $8(13.3)$ \\
$51-60$ & $12(20.0)$ \\
$61-70$ & $24(40.0)$ \\
$71-80$ & $8(13.3)$ \\
Sex [n (\%)] & \\
Male & $48(80.0)$ \\
Female & $12(20.0)$ \\
Smoking [n (\%)] & \\
Smoker & $44(73.3)$ \\
Nonsmoker & $16(26.7)$ \\
Size of lesion $[n(\%)]$ & \\
3-4 & $6(10)$ \\
$4-5$ & $8(13.4)$ \\
$5-6$ & $14(23.3)$ \\
6-7 & $18(30)$ \\
$7-8$ & $14(23.3)$ \\
Mean $\pm S D($ range) & \\
Radiological site $[n(\%)]$ & $60 \pm 1.41(3-8)$ \\
RT upper zone & \\
RT middle zone & $20(33.3)$ \\
RT lower zone & $4(13.6)$ \\
LT upper zone & $6(10)$ \\
LT middle zone & \\
LT lower zone & $2(3.3)$ \\
Complication $[n(\%)]$ & $2(3.3)$ \\
Pneumothorax & \\
Hemoptysis & \\
\hline
\end{tabular}

LT, left; RT, right.

Table 2 Presenting symptoms of patients

\begin{tabular}{lc}
\hline Symptoms & $n(\%)$ \\
\hline Dyspnea & $30(50)$ \\
Cough & $26(43.3)$ \\
Expectoration & $22(36.6)$ \\
Chest pain & $48(80)$ \\
Hemoptysis & $44(73.3)$ \\
Toxic manifestation & $14(23.3)$ \\
\hline
\end{tabular}

were successfully performed in all patients. The most frequent diagnosis was adenocarcinoma in 20 (33.3\%) patients. Regarding the final diagnosis, the percentage of malignant lesions was as follows: adenocarcinoma in $20(33.3 \%)$ patients, squamous cell carcinoma in 14 (23.3\%) patients, undifferentiated nonsmall cell carcinoma in 12 (20\%) patients, and small-cell carcinoma in two (3.3\%) patients. Percentage of benign lesions was as follows: tuberculosis in four (6.7\%) patients, organizing pneumonia in six (10\%) patients, and thymoma in two (3.3\%) patients (Table 3). 
Six (10\%) patients in whom the specimen obtained by US was nondiagnostic underwent alternative diagnostic procedures (CT-guided needle biopsy). These cases required a second biopsy to get a definite opinion. Five cases were described as nonspecific inflammatory cells in the first biopsies and underwent second biopsies, where two cases were documented to be squamous cell carcinoma, third and fourth cases were documented to be undifferentiated nonsmall cell carcinoma, and the fifth case was documented to be small-cell carcinoma. As for the remaining one, an initial report was that of the proteinaceous cast with no viable tissue, and a repeat biopsy was demanded, on which conclusive report of thymoma was obtained.

Table 3 Final histopathological diagnosis of biopsy

\begin{tabular}{lcc}
\hline Final diagnosis & $n(\%)$ & $\begin{array}{c}\text { Diagnostic accuracy of } \\
\text { initial biopsy }[N / n(\%)]\end{array}$ \\
\hline Undifferentiated nonsmall cell & $12(20)$ & $10 / 12(83.3)$ \\
Adenocarcinoma & $20(33.3)$ & $20 / 20(100)$ \\
Squamous cell carcinoma & $14(23.3)$ & $12 / 14(85.7)$ \\
Small-cell carcinoma & $2(3.3)$ & $1 / 2(50)$ \\
Thymoma & $2(3.3)$ & $1 / 2(50)$ \\
Tuberculosis & $4(6.7)$ & $4 / 4(100)$ \\
Organizing pneumonia & $6(10)$ & $6 / 6(100)$ \\
Total & $60(100)$ & $56 / 60(90)$ \\
\hline
\end{tabular}

There was a highly significant association between smoking and malignant lesions $(P<0.03)$ (Table 4). In addition, there was a highly significant association between age more than or equal to 50 years and malignant lesions, whereas no significant association was detected between the two age groups $(<50$ years and $\geq 50$ years) and benign lesions. This means that smoking and aging are risk factors for malignancy (Table 5). This also indicated that the probability of the lesions to be malignant was increased if the patient is smoker and old and the probability of the lesions to be benign was increased if the patient is a nonsmoker and young.

Regarding the final diagnosis, diagnostic accuracy was $90 \%$ (27/30), sensitivity was $96 \%$, both specificity and positive predictive value were $100 \%$, and the negative predictive value was $60 \%$ (Table 6). Complication reported in four $(6.66 \%)$ patients in the form of hemoptysis and pneumothorax (two for each). The hemoptysis stopped spontaneously without specific treatment, and pneumothorax was small, which did not require intercostal tube drainage and improved spontaneously (Table 1 ).

\section{Statistical analysis}

The data were collected, tabulated, and statistically analyzed using Stata, version 7.0 software (Stata Corp.,

Table 4 Histopathological results in relation to smoking

\begin{tabular}{lcccc}
\hline Diagnosis & Cell type & Smoker & Nonsmoker & $P$ value \\
\hline Malignant & Undifferentiated nonsmall cell & 12 & 0 & $0.003^{* *}$ \\
& Adenocarcinoma & 6 & 14 & 0 \\
& Squamous cell carcinoma & 14 & 0 & 14 \\
Total & Small-cell carcinoma & 2 & 2 & $0.049^{*}$ \\
Benign & & 34 & 0 & 0 \\
& Thymoma & 0 & 4 & 2 \\
Total & Tuberculosis & 6 & 10 & 2 \\
\hline
\end{tabular}

${ }^{*} P$ value is statistically significant. ${ }^{* *} P$ value is statistically highly significant.

Table 5 Histopathological results in relation to age

\begin{tabular}{lcccc}
\hline Diagnosis & Cell type & $<50$ years & $\geq 50$ years & $P$ value \\
\hline Malignant & Undifferentiated nonsmall cell & 2 & 10 & 18 \\
& Adenocarcinoma & 2 & 12 & $0.005^{\star *}$ \\
& Squamous cell carcinoma & 2 & 2 & \\
Total & Small-cell carcinoma & 0 & 42 & 0.548 \\
Benign & & 6 & 0 & 2 \\
& Thymoma & 2 & 4 & 2 \\
Total & Tuberculosis & 4 & 10 & 2 \\
\hline
\end{tabular}

${ }^{* \star P}$ value is statistically highly significant. 
College Station, Texas, USA). Enumeration data were presented as mean $\pm \mathrm{SD}$ and were analyzed with an

\section{Table 6 Diagnostic yield of ultrasound-guided needle biopsy}

\begin{tabular}{lc}
\hline Variables & $\%$ \\
\hline Sensitivity & 88 \\
Specificity & 100 \\
PPV & 100 \\
NPV & 62.5 \\
Accuracy & 90 \\
\hline NPV, negative predictive value; PPV, positive predictive value.
\end{tabular}

unpaired $t$ test. Categorical variables were analyzed with Pearson's $\chi^{2}$ and Fisher exact tests. $P$ value less than 0.05 was statistically considered significant (Figs 1-6).

\section{Discussion}

Transthoracic ultrasound allows thoracic lesion visualization and their structural characterization; moreover, the internal echotexture of the lesion can be evaluated with the help of color Doppler, allowing precise targeting of central necrosis in large masses [5].

\section{Figure 1}

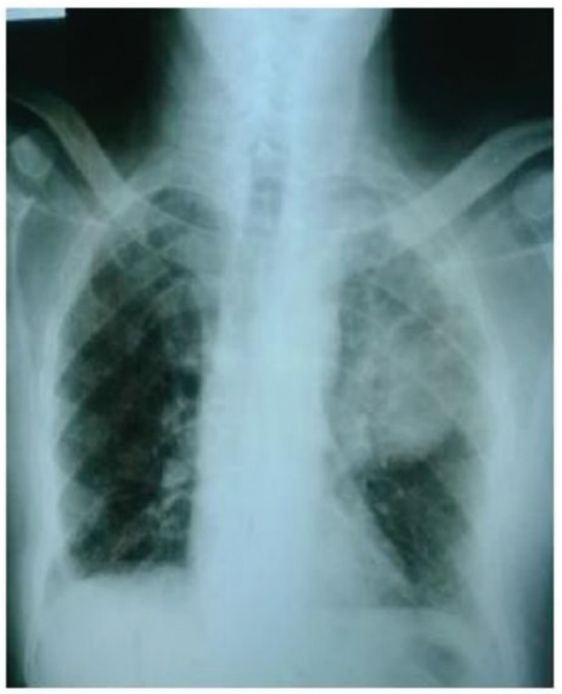

A

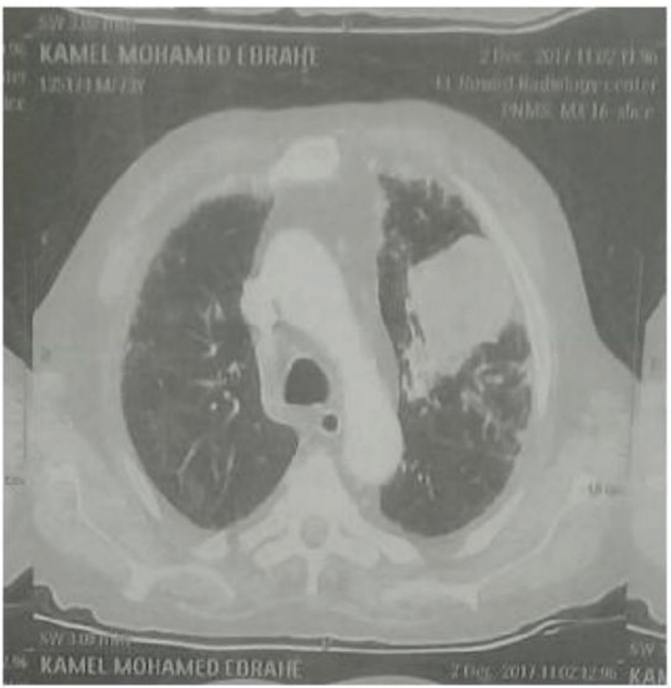

B

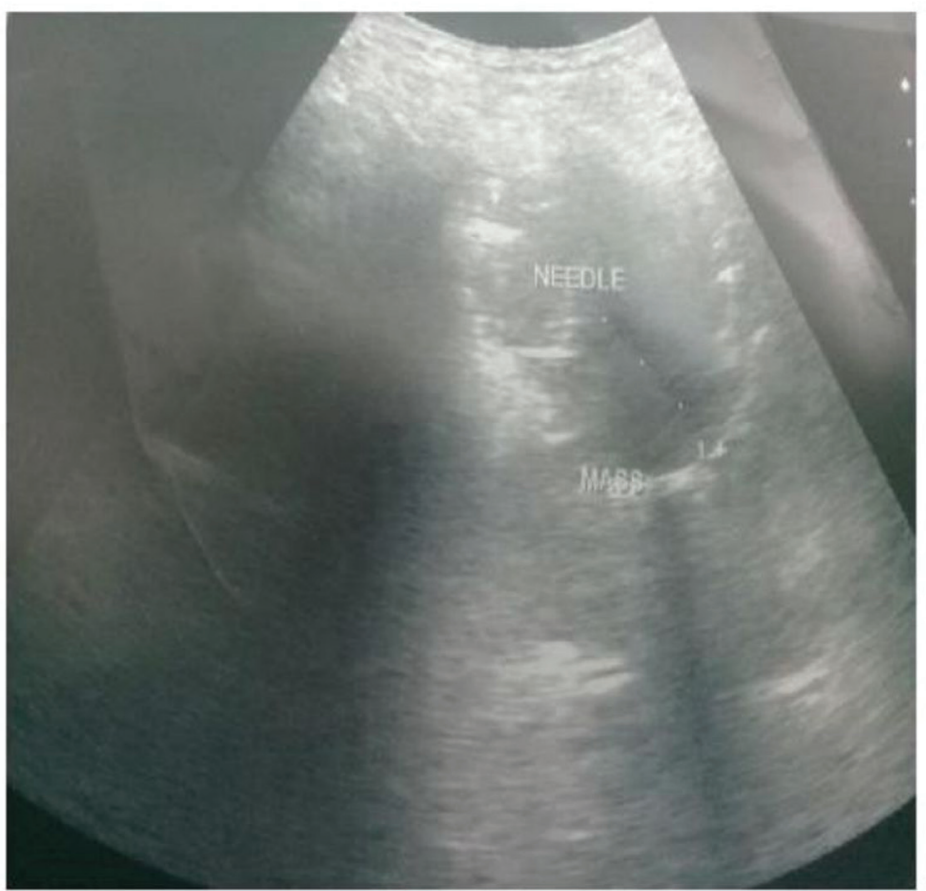

C

(a) Chest radiograph of a 63-year-old man showing upper left lobe opacity; (b) CT chest showing upper lobe mass of $5 \times 4.5 \mathrm{~cm}$; (c) US image showing TNB entering the mass. CT, computed tomography; TNB, transthoracic needle biopsy; US, ultrasound. 
Figure 2

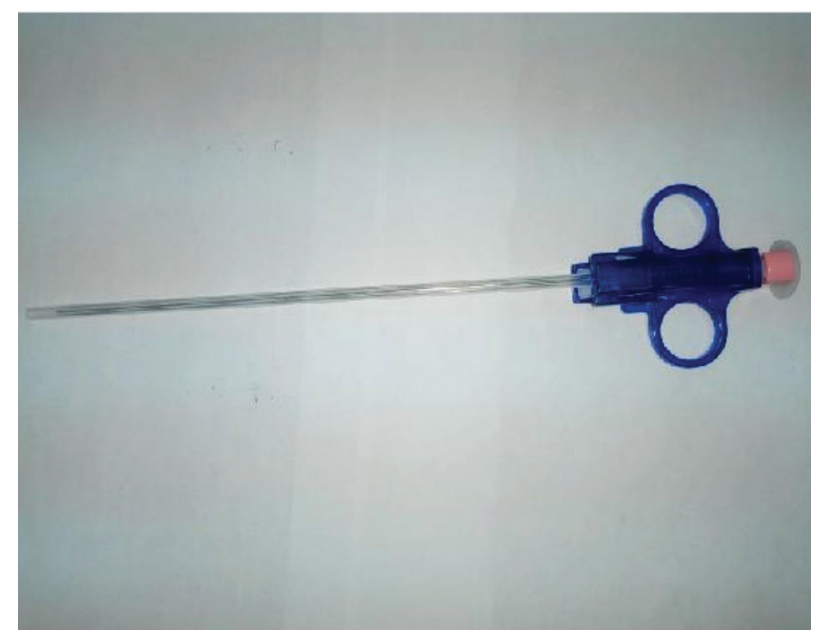

Photograph showing $18 \mathrm{G} \times 20 \mathrm{~cm}$ Tru-cut needle biopsy 46026Quistello (MN) (Italy).

Figure 3

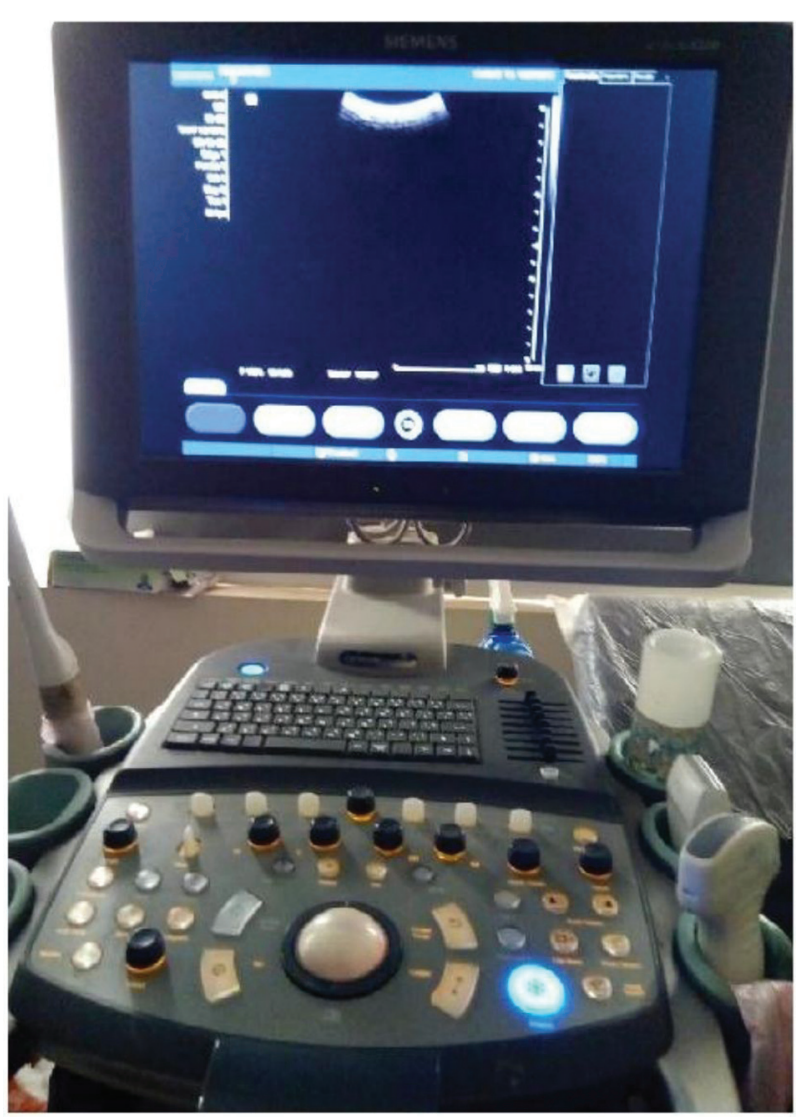

Photograph showing ultrasound Siemens Acuson, $\times 300$.

In addition, the US allows percutaneous-guided biopsies with lower risks compared with the other radiological guiding methods such as CT. The US has several advantages: no radiation exposure, accessibility, real-time monitoring, lower costs, and shorter biopsy time [6].
Figure 4

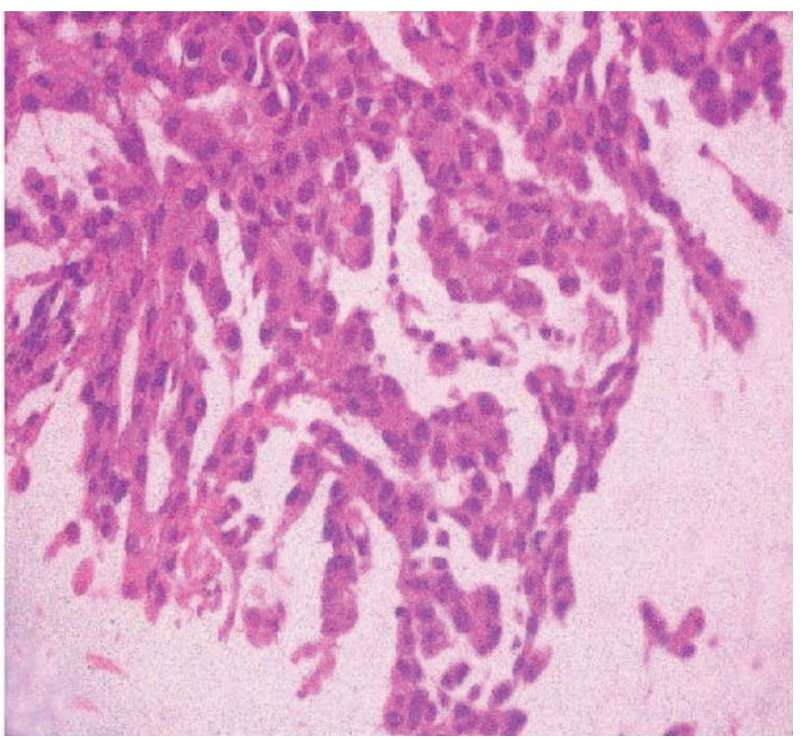

A biopsy specimen was taken from a lung mass showing moderately differentiated adenocarcinoma (hematoxylin and eosin stain, $\times 400$ ).

\section{Figure 5}

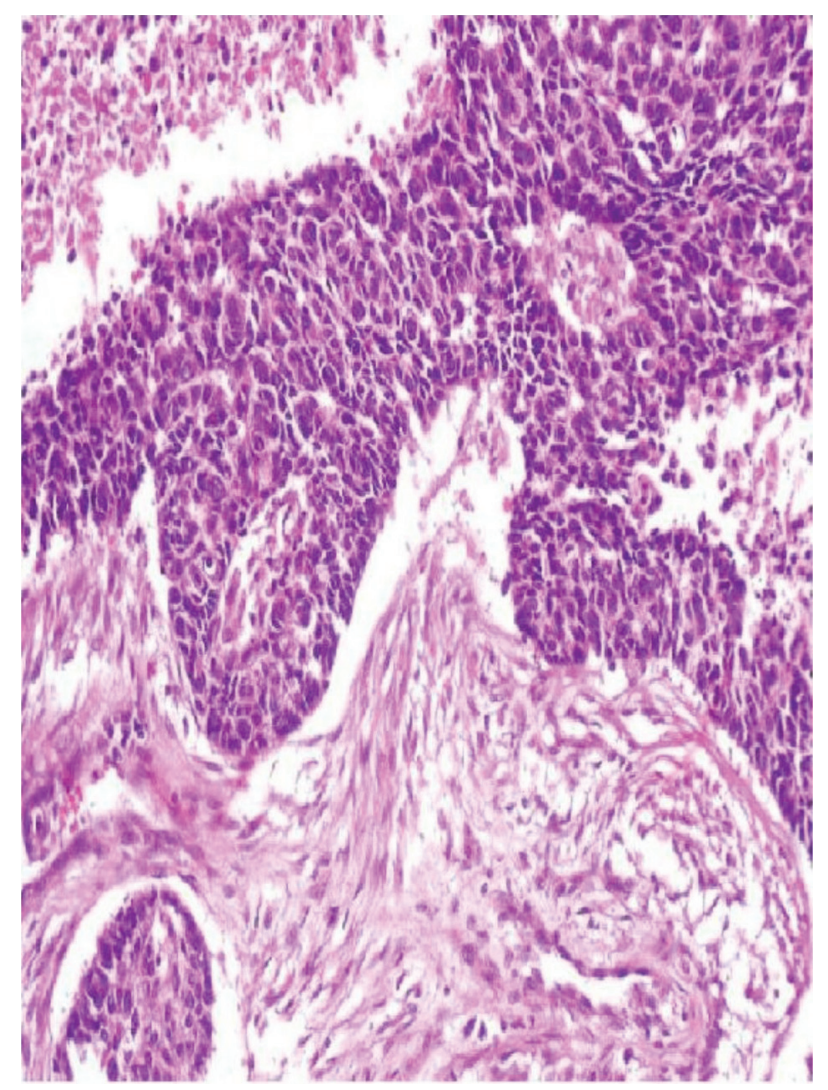

A biopsy specimen was taken from a lung mass showing poorly differentiated squamous cell carcinoma (hematoxylin and eosin stain, $\times 200)$.

However, there are some limiting factors that prohibit sonographic evaluation of the chest, which are dependent on the physical limitations of the US beam [7]. Its limitations are obscurement of lesions by aerated lungs and smaller, deep seated, and 


\section{Figure 6}

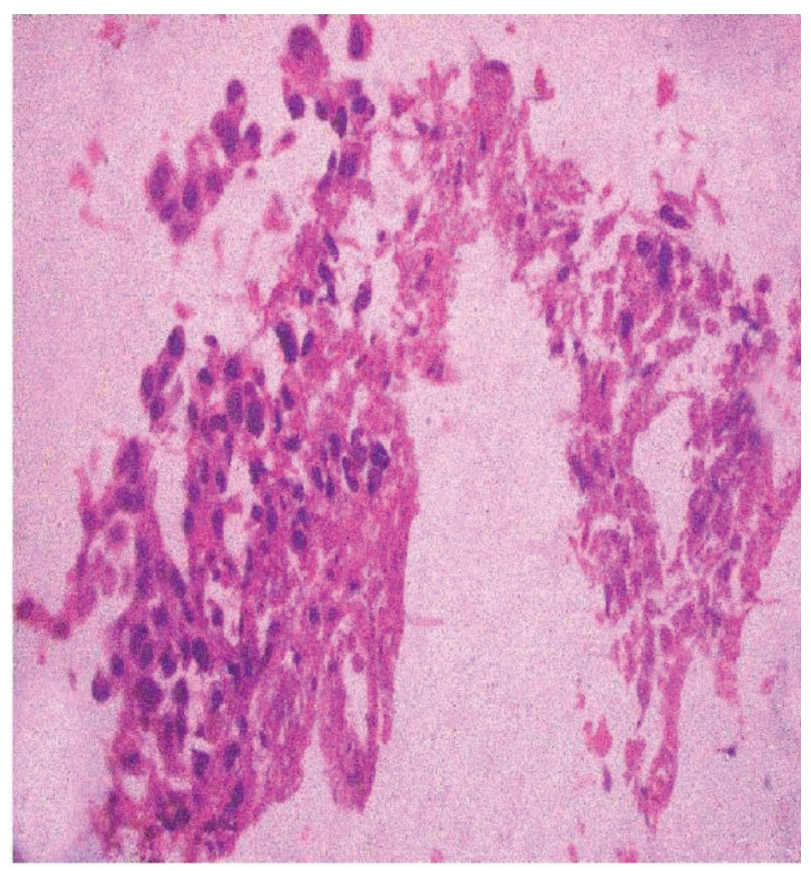

A biopsy specimen was taken from a lung mass showing small-cell carcinoma (hematoxylin and eosin stain, $\times 400$ ).

cavitary lesions. Sonography is employed for guidance in lung, and for pleural or mediastinal lesions in contact with the chest wall and CT for those not approachable by US. CT scan depicts clear anatomical details and provides access to any space of the body. It is, however, overpriced and therefore the needle is not passed in real time. CT has, among its blessings, clear depiction of anatomical details and access to any area of the body. It, however, is expensive, takes a long time to perform, and includes radiation exposure [8].

US is often as effective as CT for the guidance of thoracic biopsy of peripheral thoracic lesions. CT guidance was necessary only in cases of deeper or smaller nodules, or where the nodules were situated close to the heart and great vessels [9].

Imaging-guided transthoracic needle biopsy is a wellestablished and safe method for procurement of tissue from lung lesions, with high diagnostic accuracy, sensitivity, and specificity. With recent refinements in sonographic techniques, sonography can be as effective as CT for guiding transthoracic biopsy of peripheral chest lesions $[10,11]$.

The results of the present study showed that there were 54 (90\%) patients out of 60 patients accurately diagnosed by US transthoracic true-cut needle biopsy. In agreement with our study, Yuan et al.
[12] reported a study including 30 patients with very small pulmonary peripheral lesions with a success rate of $90 \%$. Moreover, this result was in agreement with El-Shimya et al. [13] who showed that the diagnostic yield of sonographic examination in PPLs was 90.3\%. This result was in accordance with Garcia-Ortega et al. [3]. They documented that the diagnostic accuracy of percutaneous US-guided biopsies of peripheral thoracic lesions was $90.4 \%$. This result is also consistent with a study conducted by Blank [14] who reported that the diagnostic yield exceeds $90 \%$. This result is similar to the studies by Jeon et al. [15] and Cao et al. [16] which founded that diagnostic accuracy of US-guided lung core biopsy was $89.6 \%$.

In contrast, a study by Liao et al. [10] documented that correct diagnosis was obtained in 48 (96\%) of the 50 patients. Yeow et al. [17] analyzed 631 transthoracic cutting needle lung biopsy procedures, and the results showed that the lesion size is one of the most important factors affecting diagnostic accuracy. Pulmonary lesions smaller than $1.5 \mathrm{~cm}$ or larger than $5 \mathrm{~cm}$ are associated with lower diagnostic accuracy rates. This can be explained by the fact that the presence of a higher percentage of tumor necrosis may have accounted for the lower diagnostic accuracy rate for tumors larger than $5 \mathrm{~cm}$ in diameter. In a study by Cao et al. [16], the overall diagnostic accuracy was $85.9 \%$ (104 of 121).

On the contrary, Jeon et al. [15] had shown that the overall diagnostic accuracy of US-guided transthoracic biopsy of PPLs was 91.8\% (89/97). Liao et al. [10] reported diagnostic accuracy of $96 \%$ for US-guided transthoracic biopsy of peripheral thoracic lesions, which were less than $3 \mathrm{~cm}$. According to Yang et al. [18], neither lesion location nor lesion size affected the results of US-guided needle biopsy of thoracic lesions. Muhammad et al. [19] and Jamakani et al. [20] found that the diagnostic yield of US-guided tru-cut biopsies of peripheral lesions was 98\%. Moreover, Sconfienza et al. [21] documented that the diagnostic yield of USguided biopsies of peripheral lesions was 97.1\% (100 of 103 biopsies).

Pneumothorax is a common complication, and its rate varies from 4 to $5 \%$. However, the problem must be considered dangerous [22]. Other complications like hemoptysis (4-5\%) are found to subside without intervention. Air embolism is an extremely rare complication in transthoracic needle aspiration (TTNA). It occurs when a fistula is created between a pulmonary vein and an airway [23]. Hemoptysis and pneumothorax are the foremost frequent complications 
of transthoracic biopsy and are principally delicate and self-limiting [24].In our study, two (3.33\%) patient developed pneumothorax and another two (3.33\%) developed hemoptysis. Overall complications were 6.66\%. Similar to our study, Cao et al. [16] reported that only four (3.3\%) patients out of 121 patients had mild hemoptysis. This result was in agreement with Sreelatha et al. [25] who documented that pneumothorax and hemoptysis occurred in $4 \%$ (one patient out of 22 patients for each one).

This result is closely consistent with the studies conducted by El-Shimya et al. [13], Diacon et al. [26], and Chira et al. [7], who reported that incidence of pneumothorax was $4 \%$ for US-assisted transthoracic biopsy.

In contrast, Jamakani et al. [20] founded that incidence of pneumothorax was $9 \%$ (five out of 55 patients) after US-guided biopsies. However, Jeon et al. [15] reported that post-procedural pneumothorax and hemoptysis occurred in two patients [two (2.1\%) out of 97 patients]. In addition, Grasso et al. [27] mentioned that two $(2.4 \%)$ patients showed two episodes of massive pneumothorax and four (4.8\%) patients experience low-grade hemoptysis. Sconfienza et al. [21] provided that postbiopsy pneumothorax was observed in six (5.8\%) of 103 US-guided procedures and hemorrhage occurred in one (1.0\%) of 103 USguided procedures.

Our study has several limitations. First, the number of the patients was small despite the observable variations regarding diagnosis, lesion size, and location. So, larger studies are required to identify the role of US in the diagnosis of PPLs of different etiologies. Second, there was a selection bias because only lesions that were in contact with pleural tissue were selected for biopsy. Further future study can be done on a large number of patients with peripheral lung lesions comparing the tru-cut needle with other types of needles. The last limitation to our study is the absence of a pathologist capable of making an on-thespot cytology evaluation of the lesion during the biopsy procedure.

\section{Conclusion}

The US is an effective method with high diagnostic yield for the diagnosis of any PPLs. It has many advantages such as no radiation exposure, real-time monitoring, accessibility, inexpensive, short time of biopsy, and few complications. Transthoracic needle biopsy under US guidance was a very efficient, safe, and less invasive diagnostic method for obtaining histopathological diagnosis avoiding unnecessary surgical procedures.

\section{Financial support and sponsorship \\ Nil.}

\section{Conflicts of interest}

There are no conflicts of interest.

\section{Reference}

1 Shepherd RW. A bronchoscopic pursuit of the peripheral pulmonary lesions: Navigational bronchoscopy, radial endobronchial ultrasound, and ultrathin bronchoscopy. Curr Opin Pulm Med 2016; 22: 257-264.

2 Yang PC. Ultrasound-guided transthoracic biopsy of the peripheral lung, pleural, and chest-wall lesions. J Thorac Imaging 1997; 12:272-284.

3 Garcia-Ortega A, Briones-Gomez A, Fabregat S, Martinez-Tomas R, Martinez-Garcia MA, Cases E. Benefit of chest ultrasonography in the diagnosis of peripheral thoracic lesions in an interventional pulmonology unit. Arch Bronconeumol 2016; 52:244-249.

4 Van Sonnenberg E, Goodacre BW, Wittich GR, Logrono R, Kennedy PT, Zwischenberger JB. Image-guided 25-gauge needle biopsy for thoracic lesions: diagnostic feasibility and safety. Radiology 2013; 227:414-418.

5 Sartori S, Tombesi P. Emerging roles for transthoracic ultrasonography in pulmonary diseases. World J Radiol 2010; 2:203-214.

6 Sheth S, Hamper UM, Stanley DB, Wheeler JH, Smith PA. US guidance for thoracic biopsy: a valuable alternative to CT. Radiology 1999; 210:721-726.

7 Chira R, Chira A, Mircea PA. Intrathoracic tumors in contact with the chest wall - ultrasonographic and computed tomography comparative evaluation. Med Ultrason 2012; 14:115-119.

8 Lopez Hänninen E, Vogl TJ, Ricke J, Felix R. CT-guided percutaneous core biopsies of pulmonary lesions.Diagnostic accuracy, complications, and therapeutic impact. Acta Radiol 2001; 42:151-155.

9 Moulton JS, Moore PT. Coaxial percutaneous biopsy technique with automated biopsy devices: value in improving accuracy and negative predictive value. Radiol 1993; 186:515-522.

10 Liao WY, Chen MZ, Chang YL, Wu HD, Yu-Ch J, Kuo PH, et al. US-guided transthoracic cutting biopsy for peripheral thoracic lesions less than $3 \mathrm{~cm}$ in diameter. Radiology 2002; 217:685-691.

11 Klein JS, Zarka MA. Transthoracic needle biopsy: an overview. J Thorac Imaging 1997; 12:232-249.

12 Yuan A, Yang PC, Chang DB, Yu CJ, Lee YC, Kuo SH, et al. Ultrasoundguided aspiration biopsy of small peripheral pulmonary nodules. Chest 1992; 101:926-930.

13 El-Shimya WS, El-Emerya FA, Abd El-Zahera AA, El-Badryb AM, ElSharawy DE. The diagnostic value of ultrasound-guided percutaneous transthoracic core-needle biopsy versus computed tomography-guided biopsy in peripheral intrathoracic lesions. Egypt J Broncho 2016; 10:12-19.

14 Blank W. Interventional chest sonography. In. Mathis G, ed. Chest sonography. Switzerland: Springer-Verlag; 2011. 5:187-209.

15 Jeon KN, Bae K, Park MJ, Choi HC, Shin HS, Shin S, et al. US-guided transthoracic biopsy of peripheral lung lesions: pleural contact length influences diagnostic yield. Acta Radiol 2013; 0:1-7.

16 Cao BS, Wu JH, Li XL, Deng J, Liao GQ. Sonographically guided transthoracic biopsy of peripheral lung and mediastinal lesions: the role of contrast-enhanced sonography. $J$ Ultrasound Med 2011; 30:1479-1490.

17 Yeow KM, See LC, Lui KW, Lin MC, Tsao TC, Ng KF, et al. Risk factors for pneumothorax and bleeding after CT-guided percutaneous coaxial cutting needle biopsy of lung lesions. J Vasc Interv Radiol 2001; 12:1305-1312.

18 Yang PC, Luh KT, Sheu JC, Kuo SH, Yang SP. Peripheral pulmonary lesions: ultrasonography and ultrasonically guided aspiration biopsy. Radiology 1985; 155:451-456. 
19 Muhammad H, Muhammad A, Kamran KC. Diagnostic yield of ultrasoundguided true-cut biopsies of peripheral lesions by the pulmonologist. Ann Pak Inst Med Sci 2015; 11:215-217.

20 Jamakani M, Duguay S, Rust K, Conner K, Wagner JM. Ultrasound versus computed tomographic guidance for percutaneous biopsy of chest lesions. J Ultrasound Med 2016; 35:1865-1872.

21 Sconfienza LM, Mauri G, Grossi F, Truini M, Serafini G, Sardanelli F, et al. Pleural and peripheral lung lesions: comparison of US- and CT-guided biopsy. Radiology 2013; 266:930-935.

22 Charig MJ, Phillips AJ. CT-guided cutting needle biopsy of lung lesions safety and efficacy of outpatient service. Clin Radiol 2002; 55:964-969.

23 Yildirim E, Kirbas I, Harman A, Ozyer U, Tore HG, Aytekin C, et al. CTguided cutting needle lung biopsy using modified coaxial technique: factors affecting the risk of complications. Eur $J$ Radiol 2009; 70:57-60.
24 Khan MF, Straub R, Moghaddam SR, Maataoui A, Gurung J, Wagner TO, et al. Variables affecting the risk of pneumothorax and intrapulmonal hemorrhage in CT-guided transthoracic biopsy. Eur Radiol 2008; 18:1356-1363.

25 Sreelatha PR, Raghavan S, Naveen N, Venugopal K. Diagnostic yield of ultrasound-guided transthoracic fine needle aspiration biopsy in the diagnosis of intrathoracic lesions. Kerala Med $\mathrm{J}$ 2017; 10:18-24.

26 Diacon AH, Schuurmans MM, Theron J, Schubert PT, Wright CA, Bolliger CT. Safety and yield of ultrasound-assisted transthoracic biopsy performed by pulmonologists. Respiration 2004; 71:519-522.

27 Grasso RF, Luppi G, Giurazza F, Faiella E, Cazzato RL, Zobel BB, Rome T. Lung core biopsy US-guided: approach to characterize subpleural lesions. Eur Radiol 2013; 23:3071-3076. 